
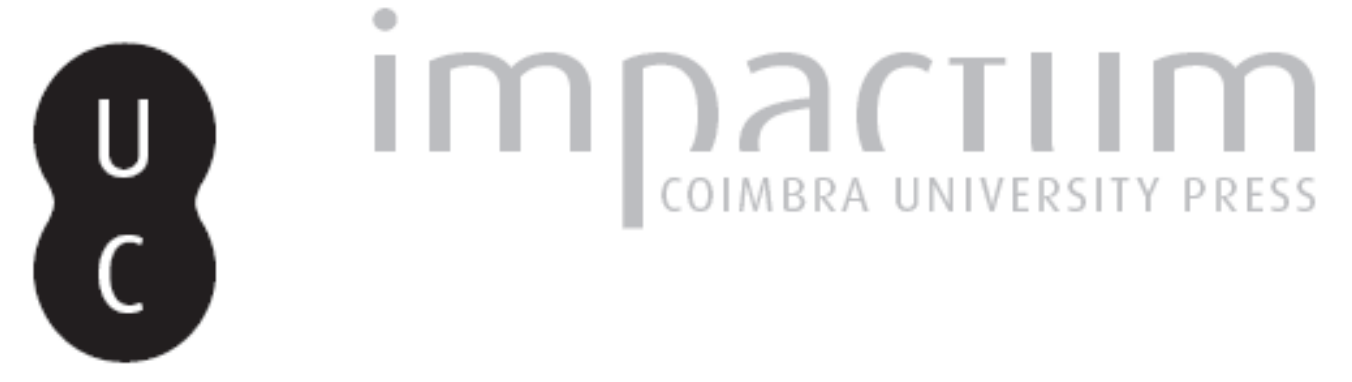

\title{
Concursos de arquitetura: uma experiência no atelier de projeto
}

\section{Autor(es): Kuchpil, Eneida}

Publicado por: Editorial do Departamento de Arquitetura

URL persistente:

URI:http://hdl.handle.net/10316.2/37264

DOI:

DOI:http://dx.doi.org/10.14195/1647-8681_4_13

Accessed : $\quad$ 26-Apr-2023 06:24:03

A navegação consulta e descarregamento dos títulos inseridos nas Bibliotecas Digitais UC Digitalis, UC Pombalina e UC Impactum, pressupõem a aceitação plena e sem reservas dos Termos e Condições de Uso destas Bibliotecas Digitais, disponíveis em https://digitalis.uc.pt/pt-pt/termos.

Conforme exposto nos referidos Termos e Condições de Uso, o descarregamento de títulos de acesso restrito requer uma licença válida de autorização devendo o utilizador aceder ao(s) documento(s) a partir de um endereço de IP da instituição detentora da supramencionada licença.

Ao utilizador é apenas permitido o descarregamento para uso pessoal, pelo que o emprego do(s) título(s) descarregado(s) para outro fim, designadamente comercial, carece de autorização do respetivo autor ou editor da obra.

Na medida em que todas as obras da UC Digitalis se encontram protegidas pelo Código do Direito de Autor e Direitos Conexos e demais legislação aplicável, toda a cópia, parcial ou total, deste documento, nos casos em que é legalmente admitida, deverá conter ou fazer-se acompanhar por este aviso.

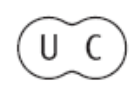




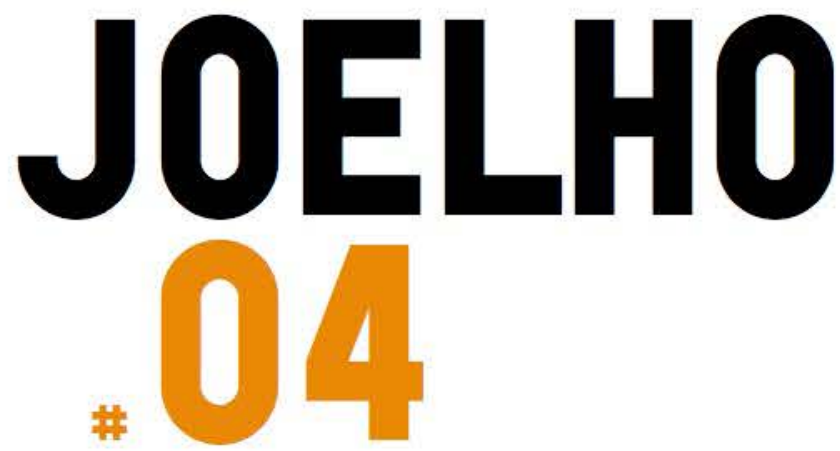

\section{ENSINAR PELO PROJETO \\ TEACHING THROUGH DESIGN}

\section{Coordenaçẫo:}

Paulo Providência

Gonçalo Canto Moniz

Alexandre Alves Costa Juan Domingo Santos Florian Beigel Philip Christou Elizabeth Hatz David Leatherbarrow Andrew Clancy Colm Moore Michael McGarry Willemijn Wilms Floet

Exposição TAPE 20Ir-12 


\section{Eneida Kuchpil \\ Concursos de arquitetura. Unma experiência no Âtelier de Projeto}

Num cenário caótico de uma desenfreada proliferação de escolas de arquitetura no Brasil, muitas delas alheias às noções do que se entende por arquitetura de excelência, os problemas relativos ao ensino se apresentam ainda mais complexos. $O$ Curso de Arquitetura da Universidade Federal do Paraná (CAUUFPR) foi criado em 1962 num momento singular da história do país. A moderna arquitetura brasileira adquiria maturidade e reconhecimento mundial, entre outras obras pela construção de Brasília, e o governo federal, respondendo à sociedade civil organizada, ampliou a rede pública de ensino superior criando centros de formação em arquitetura.

No contexto histórico de origem dessa escola encontra-se o desenvolvimento econômico e social do Estado do Paraná e de sua capital Curitiba. Para o funcionamento da escola de arquitetura local foi necessário migrarem arquitetos de diferentes regiões e tradições acadêmicas. Parte significativa dos professores e arquitetos pioneiros vieram de outros estados como São Paulo e Rio de Janeiro.

Os anos 70 e 80 foram de intensa atividade projetual para os arquitetos paranaenses. $\bigcirc$ curso e a profissão ganharam visibilidade e importância através da bem sucedida participação desses profissionais (professores, alunos e ex-alunos do curso) em diferentes áreas de atuação. A legitimação social referida pode ser atribuída a muitos fatores: a ampliação do mercado de trabalho; as diversas premiações obtidas pelos arquitetos e professores do curso em concursos de arquitetura desde os anos 60 até o final dos 70; a bem sucedida administração municipal do arquiteto Jaime Lerner

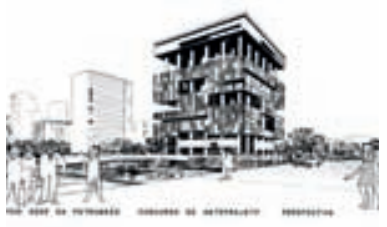

1. $1^{\circ}$ prêmio - Concurso Edifício Sede da Petrobras (1968).

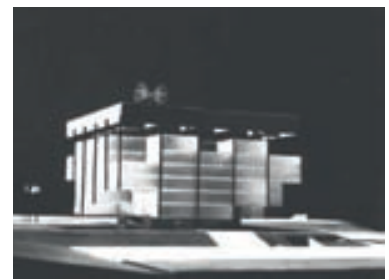

2. $1^{\circ}$ prêmio - Concurso Edifício Sede BNDE DF (1973). na prefeitura de Curitiba e a institucionalização do processo de planejamento urbano nessa cidade; e as transformações na paisagem das cidades paranaenses oriundas de projetos e planos urbanísticos capitaneados por equipes de arquitetos.

É em torno do CAUUFPR que se estabelece um capítulo bastante especial na história da arquitetura moderna brasileira. Arquitetos, professores, ex-alunos realizariam trabalhos em grupos abertos e alternantes. Uma das faces mais visíveis dessa produção estaria na participação em concursos nacionais de arquitetura, modalidade em que conquistariam quase uma centena de premiações, dos quais trinta e dois primeiros lugares e trinta segundos prêmios.

Em três concursos nacionais, Banco do Brasil de Caxias do Sul (1970), BNDE DF (1973) e o Terrafoto de São Paulo (1979), os paranaenses conquistariam quatro dos cinco prêmios finais oferecidos. O auge dessa expressão ocorreria junto à esplanada do Santo Antônio, no Rio de Janeiro, local em que arquitetos de Curitiba projetariam torres de escritórios destinadas a duas importantes sedes estatais: o Edifício da Petrobrás (1968) (fig.1) e o Edifício do BNDES (1974) (fig.2).

Pode-se afirmar que a história da moderna arquitetura paranaense deve suas origens à criação do CAUUFPR, os arquitetos formados nessa escola militaram simultaneamente em funções de ensino e pesquisa na universidade, de projetistas em seus escritórios e agências públicas, e na direção e gestão de organismos e políticas oficiais, postos de atuação decisivos para traduzir os anseios e necessidades da população em propostas de ação edificáveis.

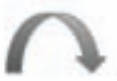

cowentia concaets

testua os conceitos eM novas sturcoes

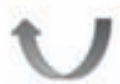

ronmacio of concertos

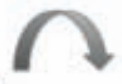

3. Modelo Kolb - 1984. oesehvacoes E AEFLDOES

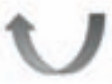


A redefinição da estratégia pedagógica do CAUUFPR foi simultânea às transformações arquitetônicas e urbanísticas vividas no processo de urbanização e metropolização da cidade. A cidade de Curitiba foi um laboratório. $O$ conhecimento arquitetônico sobre o edifício, a cidade e a paisagem identificáveis nos projetos e intervenções que transformaram o ambiente da metrópole não representam uma simples cópia ou adaptação dos paradigmas e estilos arquitetônicos - eles são a cultura de referência de nossos aprendizados, o domínio do desenho é o que caracteriza a especificidade do arquiteto frente as seus pares e interlocutores na sociedade local e nacional, correspondendo à tradição e à cultura do ensino dessa matéria no CAUUFPR.

\section{O papel da metodologia do projeto da prática projetual} O processo de projeto mantém-se repleto de operações que conformam a concepção arquitetônica do edifício, que se repetem ao longo dos anos confirmando a sua resistência disciplinar. Com muitas maneiras de conduzir este processo, abrem-se novos horizontes de reflexão, comparações e debates estreitando os elos entre reflexão e prática projetual. $O$ tema não remete somente a como projeta um arquiteto, senão a como se aprende a projetar. E, diminuída a ênfase no objeto isolado, a arquitetura deve propor um diálogo mais responsável com a cidade, isso justifica a busca de uma nova abordagem do processo de concepção.

Para Walter Gropius o método do projeto permite que o arquiteto seja capaz de encontrar seu próprio caminho, quaisquer que sejam as circunstâncias, que ele seja capaz de criar independentemente formas autênticas, a partir de condições técnicas, econômicas e sociais a ele dadas, em vez de impor uma fórmula aprendida a um ambiente que talvez exija uma solução completamente diversa (Gropius, 2004). Nessa linha, as disciplinas de projeto de arquitetura nas escolas brasileiras conduzem seus trabalhos, pois como ressalta Mahfuz (2004), embora muitos digam que o projeto não pode ser ensinado, "certamente ele pode ser aprendido".

A multiplicidade de aspectos a serem considerados na resolução de qualquer problema de arquitetura tem dificultado sobremaneira a obtenção de proposições satisfatórias. Objetivando investigar as possíveis aproximações de projeto, adotou-se uma estratégia projetual no contexto da escola, resgatando os concursos de arquitetura e enfatizando nesta estratégia os principais entendimentos que devem ser consolidados pelo aluno na concepção do projeto - o lugar, o programa na esfera da sociedade hipertextol e em especial a tectonicidade. O termo "estratégia" deve ser compreendido como "mecanismos, procedimentos, paradigmas e artefatos formais que aparecem com insistência recorrente nas obras dos arquitetos contemporâneos: entendendo que os utilizem para configurar o construído" (Moneo, 2008).

Para Piñon (2008), "não há projeto sem matéria". O conceito e a técnica - a idéia e a razão - não são pólos de uma oposição irreconciliável. A essência do ensino de projeto é a criação e proposição de exercícios cuja realização permitirá ao estudante

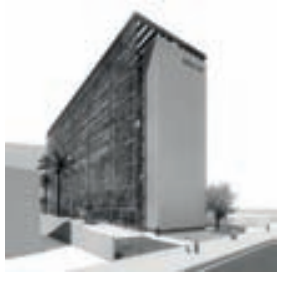

4. $1^{\circ}$ prêmio - Concurso Edifício Sede CREA-PR (2009).

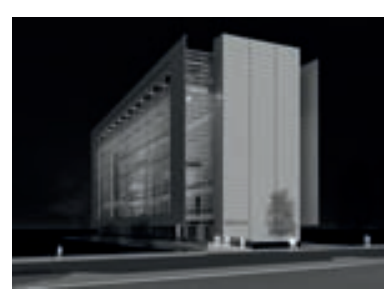

5. $1^{\circ}$ prêmio - Concurso Edifício Sede CREA-PR (2009). desenvolver a habilidade de projetar, apresentando aos estudantes modos possíveis de solução dos problemas projetuais, apoiados em casos exemplares. Considerando tanto para os aspectos formais/ organizacionais do projeto quanto para os técnico-construtivos.

Mahfuz (2009) afirma que o ensino de arquitetura deveria sempre se basear na própria arquitetura. Assim, o que podemos realmente transmitir - tentando facilitar o aprendizado por cada estudante - é o ofício da arquitetura, materializado nos projetos e edifícios que nos cercam ou que podemos conhecer por meio das mais variadas mídias. Para aprender o ofício da arquitetura é necessário envolvimento direto e constante com a sua matéria prima: seus edifícios e projetos.

Helio Piñon (2006) sugere que “o aprendizado de projeto deveria ser pensado como uma (re)construção de materiais da arquitetura, guiada por critérios extraídos das próprias obras sobre as quais se atua". Dito de outro modo a noção de projeto como (re)construção significa "a construção de uma nova ordem a partir de matéria prima verificada empiricamente".

O que ele sugere é o envolvimento direto com os precedentes, seja pelo re-desenho ou pela atuação direta sobre um projeto. Normalmente tomamos como ponto de partida o programa para chegar ao objeto, a proposta de Piñón inverte o processo, propondo que se descubra a lógica do programa a partir da identificação da ordem do edifício.

A adoção de um edifício de reconhecida qualidade como objeto de reflexão fornece materiais de projeto - elementos e critérios de ordenação - que permitem a elaboração posterior dos mesmos materiais em situações variadas. Ao fixar o olhar sobre um universo ordenado, o estudante é levado a reconhecer os critérios de construção formal e material que determinam sua aparência. Além disso, "abordar a arquitetura a partir dos edifícios - e não somente desde os programas - tem a vantagem de mostrar a relevância da dimensão visual da concepção em comparação com o hábito de fazer referência a conceitos legitimadores".

As vantagens do re-desenho de arquiteturas exemplares podem ser ampliadas se estabelecermos como exercício a investigação de supostas alterações do programa original: isso permitirá ir além do reconhecimento do sistema e passar à exploração de suas capacidades operativas.

Vitrúvio (Livro Primeiro / capítulo I) já colocava a questão “...Arquitetura é uma ciência que surge de outras ciências, adornada com muitos e variados aprendizados com a ajuda dos quais se forma um julgamento daquelas obras que são resultado de outras artes. Pratica e teoria são seus pais ...o arquiteto prático não é capaz de encontrar razão nas formas que adota e o teórico também falha, apreendendo sombras ao invés de substancia ..."

Qualquer um que se confronte com o desafio de discutir o ensino da arte de projetar seja arquitetura, desenho industrial ou urbanismo terá que admitir a própria dificuldade em chegar a uma definição satisfatória para as noções de concepção projetual, projeto como processo, projeto como produto, idéia, problema, programa, conceito,

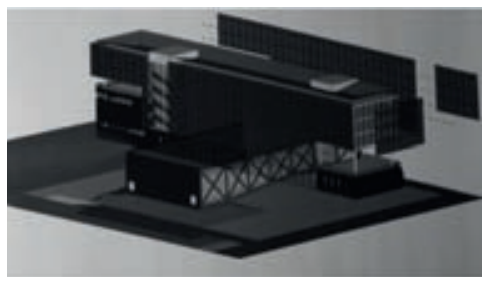

6. Proposta Alunos CAUUFPR (2012). 
partido, desenho, design (ou disegno) só para citar alguns dos termos que gravitam em torno da questão central 'projeto'. Ainda assim, essa dificuldade não impede, de forma alguma, o desenvolvimento das atividades profissionais nesse campo e das diversas abordagens teóricas em torno delas. (Barki in Oliveira et al., 2009)

Talvez fosse importante reconhecer que o propósito da educação na arquitetura seria o de cultivar o legado de conhecimentos e habilidades visando preparar 'eternos estudantes', inspirados pela realidade das necessidades humanas que a arquitetura - como ofício, prática e pensamento - deve tratar. Schon (1983) em seu trabalho The reflective practitioner, descreve o processo de concepção como um percurso de reflexão na ação, entende a concepção como uma prática baseada no aprendizado através das próprias experiências mais do que uma transferência de conhecimento (fig.3).

\section{Concursos de projeto de arquitetura e suas oportunidades para o ensino de projeto}

A arquitetura é uma disciplina que necessita materializar inter-relações e interações. Nesse sentido, os concursos públicos de projetos de arquitetura ajudam a promover questionamentos transdisciplinares sobre o "pensar e fazer" da profissão.

Os concursos também materializam propostas sobre um fazer arquitetônico nos quais se relacionam às tecnologias de seu tempo, sem menosprezar o contexto no qual se inserem e os indivíduos aos quais se destinam.

A experiência de utilizar, com os alunos do último ano do CAUUFPR, os concursos como objeto de estudo tem se mostrado eficaz na Disciplina de Projetos Especiais, atendendo os objetivos da disciplina: Prática da metodologia de elaboração de projetos de arquitetura que abordem a variedade de organizações espaciais possíveis num dado programa arquitetônico de maior complexidade, discutindo e analisando a exeqüibilidade e viabilidade da solução espacial proposta."

A partir do edital de um Concurso já realizado propõem-se o desenvolvimento do exercício atendendo o mesmo programa que deverá ser implantado em terreno com características distintas do objeto analisado, como no caso do Concurso de Arquitetura para a Sede do Conselho Regional de Engenharia e Agronomia do Paraná - CREAPR, na cidade de Curitiba, Paraná. Observando os projetos premiados o local foi determinante na geração dos partidos. (fig.4, 5).

O trabalho de atelier é desenvolvido mediante algumas etapas seqüenciais, avaliadas segundo distintos critérios, de acordo com a importância e a complexidade de cada parte. A avaliação das propostas dos alunos contempla os itens: IMPLANTAÇÃo (referências urbanas e preexistências), PROGRAMA (aspectos funcionais e dimensionais), PARTIDO (aspectos plásticos e espacialidade), LEGISLAÇÃO, TÉCNICAS CONSTRUTIVAS, CONFORTO AMBIENTAL e a APRESENTAÇÃo (expressão gráfica, legibilidade do projeto).

O projeto torna-se instrumento de transformação das relações existentes no sítio; procura o confronto com as permanências, para modificar as regras de pertencimento do espaço. Com o estudo a partir de um novo terreno, a proposta do aluno contempla uma nova paisagem vista como "a soma total de todas as coisas" geográficas e históricas. (Gregotti in Nesbitt, 2006), coloca a discussão do lugar como fruto de um processo cognitivo, mediado pelas representações do imaginário social, pleno de valores simbólicos. A paisagem apresentase assim de maneira dual, sendo ao mesmo tempo real e representação.

Conhecer e reconhecer os diversos modos contemporâneos de produção e consumo da imagem dos centros das cidades tradicionais é condição indispensável à compreensão de algumas transformações relevantes do espaço urbano. A produção do espaço urbano contemporâneo demonstra um individualismo e fragmentação, opostos que parecem conviver como pressupostos do pensar a cidade hoje. Neste espaço de oposição, em que convivem um projeto político que aponta para a sociedade e um ideal democrático e o espaço da fragmentação e do não lugar, para usar a expressão instigante de Marc Auge, está inserida a arquitetura contemporânea. (Abascal, 2007)

Conforme argumenta Solà-Morales, na história das cidades, a obra arquitetônica, enquanto forma dos edifícios, sempre esteve incorporada a intencionalidade urbana. Qual os limites e possibilidades que a arquitetura desempenha nesses novos lugares, que são a uma só vez ausência e território.

O exercício ocupa um semestre do curso. A etapa inicial, refere-se à pesquisa e análise de todo o processo do concurso em especial dos projetos vencedores, que, por sua vez, deve ser seguida pela proposta através do Estudo Preliminar e Anteprojeto e do projeto executivo.

Na primeira etapa, além das análises do local e formais, é realizada a elaboração de um diagrama funcional que deriva diretamente do programa arquitetônico e salienta funções e relações entre diversos componentes espaciais do programa identificando a proximidade e dimensões relativas de diferentes zonas de atividade. A partir desse modelo surgem outros diagramas que analisam de maneira especifica: áreas, fluxos de circulação, intensidade de uso, função dos espaços, relações de dependência entre ambientes e as prioridades do programa. Em geral, o desenvolvimento a partir desses diagramas pode conduzir a um reprograma e um plano, ainda em fase embrionária, com outras informações adicionadas. Esse processo evolutivo pode mostrar a transição entre uma "geometria de posição", puramente relacional para uma geometria mais rigorosa, com a introdução de medidas e características formais.

Operando a partir do "desmonte" de realidades e significações dadas, pode-se revelar conjunturas inesperadas. Mais do que expor, estimula e provoca a imaginação; mais do que "explicar" situações existentes, apresenta possibilidades para o desenvolvimento das proposições das etapas posteriores.

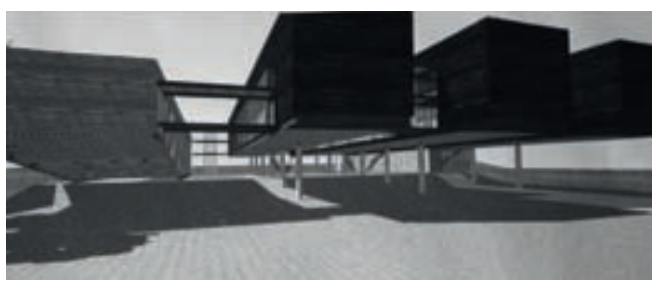

7. Proposta Alunos CAUUFPR (2012).

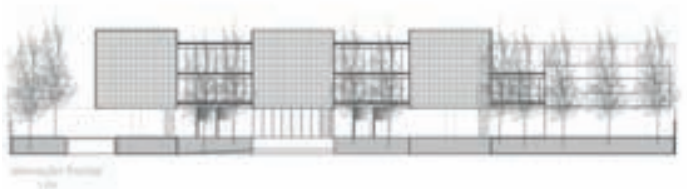

8. Proposta Alunos CAUUFPR (2012).

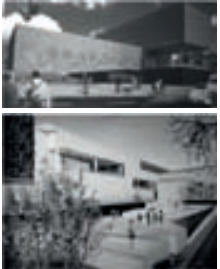




\section{Conclusões}

O exercício tenta superar a noção equivocada de que o artista inventa a seu gosto. A qual, aplicada à arquitetura, leva a uma idéia enganosa da invenção necessária e permanente, quando na verdade a maioria dos edifícios repete com variações outras experiências (Martínez, 1998).

A função principal do exercício descrito está em capacitar o aluno a fazer escolhas racionais, busca-se diminuir a aleatoriedade das ações, substituindo-as por metodologias flexíveis e adaptáveis a cada caso. O desafio consiste em como dosar os aspectos técnicos e racionais em relação aos artísticos.

Esta experiência acadêmica reitera assim, a afirmação de Piñon (2008), de que a confluência, em um projeto, de critérios de ordem que aspiram à universalidade e um programa específico, no âmbito de um lugar singular, provoca uma arquitetura com identidade específica quanto a sua estrutura forma e universal, com respeito aos valores que lhe dão consistência (fig.6, 7, 8, 9 e 10).

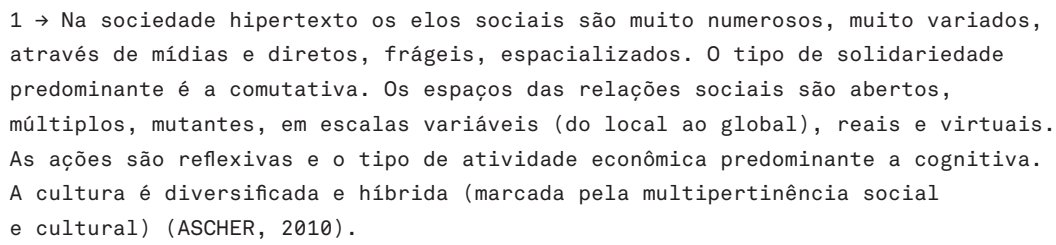

\section{Referências Bibliográficas}

Cullen, G. (1983). Paisagem Urbana.

Lisboa: Edições 70.

Gropius, W. (2004). Bauhaus: Novarquitetura. São Paulo: Perspectiva.

Mahfuz, E. C. (2009). O ateliê de projeto como mini-escola., São Paulo: www.vitruvius.com.br/ revistas/read/arquitextos/10.115/1.

Martínez, A.C. (1998). Ensayo sobre El Proyecto. Buenos Aires: Librería Tecnica CP67 S.A..

-

Moneo, R. (2008). Inquietação teórica e estratégia projetual. São Paulo: Cosac Naify.
Nesbitt, K. (2006). Uma Nova Agenda para a Arquitetura. São Paulo: Cosac \& Naify Edições.

Piñon, H. (2006). Teoria do Projeto. Porto Alegre: Livraria do Arquiteto.

Oliveira, B.S. et al. (2009). Leituras em Teoria da Arquitetura, vol. 1. Rio de Janeiro: Vianna \& Mosley Editora.

Pacheco, P. C. B. (2011). A arquitetura do Grupo do Paraná: 1957-1980. [Tese de doutoramento]. Porto Alegre: Faculdade de Arquitetura da UFRGS, PROPAR.
Solà-Morales, I. (2002). Territórios. Barcelona: GG.

Segre R. et al. (2010). Arquitetura+Arte+Cidade: um debate internacional. Rio de Janeiro: Vianna \& Mosley Editora.

-

Portal de Concursos de Projeto. Concurso CREA $P R$ - Curitiba. Consultado em 20 de agosto de 2010. www.concursosdeprojeto.org/2009/06/07/ concurso-nacional-crea-pr-resultado.

Vitruvio, Da Arquitetura, tradução e notas de Marco Aurélio Lagonegro, introdução de Júlio Roberto Katinsky (1999). Sao Paulo: Editora Hucitec, Fundação para a Pesquisa Ambiental. 